\title{
Analysis of Biometric Technology Adaption and Acceptance in Canada
}

\author{
Eesa Al Solami \\ University of Jeddah, \\ Saudi Arabia
}

\begin{abstract}
This study aimed at analyzing the analysis biometric technology adoption and acceptance in Canada. From the introduction, the paper reveals that biometrics technology has been in existence for many decades despite rising to popularity in the last two decades. Canada has highly advanced in information technology. It is observed that the three sectors for the adoption and acceptance of biometric technologies are: financial services, immigration, and law enforcement. The study uses judgment for sampling and questionnaires for the collection of data. Given the high rate of adoption and acceptance of biometric technologies in Canada, the paper concludes that the adoption of these technologies is at the adaptation state. Age and experience also influence the rate at which individuals accept biometric technologies with the most experienced participants showing the highest rate of approval.
\end{abstract}

Keywords-Adaption; biometric technology; organizational

\section{INTRODUCTION}

In the modern business environment, competition leaves organizations with no chance but use all the resources that are at their disposal to gain competitive advantage. One of the fronts where this kind of competition has been evident is technological. In most cases, the organizations that have innovative technologies carry the day. One of the most discussed technologies in business is the biometric technology. Biometric is the measure of the unique physical and behavioral traits. The use of biometrics for identification and security has become a common practice, especially in developed countries. The use of biometrics for authentication is one of the most secure and trusted options for user authentication. Various factors always influence the rate at which a technology such as biometric authentication is adopted in a country. This paper analyses biometric technology adoption and acceptance in Canada.

The paper is organized as follows. The next section highlights the Information technology investment in Canada. In Section 3, we present the literature review of the topic be explaining the mannerism of identification and use. Also, we shows how the adoption of biometric security systems. In Section 4, we present the theoretical framework. Following this in Section 5, we explain the methodology of the work by defining the way of sampling, shows how is the data collection and also, the approach of data processing. In Section 6, we presents the data presentation and analysis and emphasis the regression analysis. Following this in Section 7, we show the discussion of results. The final section concludes the paper.

\section{A. Contribution}

In this paper, we analysed and studied biometric technology adoption and acceptance in Canada. The paper concluded that three sectors in Canada where the adoption and acceptance of biometric technologies are financial services, immigration, and law enforcement. Furthermore, there are two main factors including age and experience influence the rate at which individuals accept biometric technologies with the most experienced participants showing the highest rate of approval.

\section{INFORMATION TECHNOLOGY IN CANADA}

Canada may not be a country that comes to the mind of any one with the mention of economic superstars, but it is one of the best-managed economies in the world. For many years, the government of Canada has put importance in the use of information technology for economic sustainability. The government of Canada Information Technology Strategic Plan 2016-2020 is one of the evidence of the extent to which the government has gone to make sure that the use of information technology in the country is complemented. This is according to a study that was done by [3]. Information technology has been of the most contribution to the growth of the main services sector in Canada. According to a report by The Information and Communications Technology Council (ICTC), aside from job creation and direct contribution to the GDP through the ICT sector that increased by $\$ 2$ billion in 2014, the contribution of ICT to the other sectors is beyond doubt. The proximity of the country to the US and their close business relationship has also contributed to the high rate of advancement of ICT in the country.

\section{LITERATURE REVIEW}

Despite biometric being on the verge of a breakthrough in human identification and security, it was not given much consideration as it is given in the modern society. Canadian stakeholders believe that there are benefits that come with the use of biometric technologies [5]. However, with all these advantages there are disadvantages such as age and occupational factors that may lead to difficulty in capturing physical attributes such as fingers. People in occupations such as construction are prone to such a disadvantage. The various biometric technologies can be judged in terms of universality, permanence, uniqueness, collectability, acceptability, performance, and circumvention. However, assert that none of these technologies is perfect. When they are reviewed in terms of the above-mentioned factors of judgment, there are some shortcomings that are noted for the use of biometrics as shown in Table I.

Table I reveals the imperfection of the biometrics that is used in Canada. Therefore, there is always a system that can be used in the evaluation of the performance of a biometric 
system. The system has three criteria, which are: 1) False accept rate (FAR): the proportion of unauthorized users manage to get access. Such error is most likely to be as a result of a security breach. a) False reject rate (FRR): the proportion of authorized users that fail to get access. Such an error represents threats the rightful use of the system. b) Crossover error point (CEP): a scenario whereby the rate of false acceptances equals is equal to the rate of false rejections. Such and error implies optimal results to biometrics-based systems.

\section{A. Mannerism of Identification and Use}

Of the forms of biometrics that are used in various parts of the world, fingerprints have been used in Canada for the longest period. This technology has been particularly used in the finance sector in the identification of account holders for the sake of securing accounts from possible fraud [10]. In [9] asserts that there has been a significant decrease in the rate of fraud cases that relate to false acceptance. For the sake of security, some organization is fingerprint recognition that requires the use of all the ten fingers instead of just one because it enhances accuracy.

Another biometrics that is commonly used in Canada is facial recognition. This technology was initially manual with the administrators have to look at digital pictures for facial confirmation. However, with the advancement in technology in Canada, facial biometrics technology has been taken to a whole new level. A perfect example is the application of facial recognition at Canadian airports [13]. This is part of the program that was introduced by a traveler screening program by the Canadian Border Services Agency. This involves selfservice border clearance kiosks that intend to make Canadian border points safer.

In [2] asserts that many people do not realize that Iris recognition is different from facial recognition. Iris is a muscle that performs the function of controlling the size of the pupil. The highly detailed texture makes it possible for Iris to be used for identification and authentication. Government agencies have been on the frontline in using Iris identification in Canada. An example of such a case is the partnership between IBM and ID Iris to provide iris recognition technology for NEXUS, a program under the Canadian Border Services Agency [8]. The private sector has also used this technology for authentication is some occasions.

Voice recognition technology has also been used by some organizations. This is an assertion that is true as far as the financial sector in Canada is concerned. RBC was the first Canadian company to successfully implement the voice recognition technology in 2015. However, that is not where the application of voice recognition technology ends. Soon, many other organizations were using this technology for recognition. The financial sector has been under pressure to use innovative technology in the recent past because of the changing expectations of their customers.

\section{B. Adoption Biometric Security Systems}

Despite many people not being opportunistic on the adoption of biometric technologies in Canada, the adoption rates have been relatively high as organizations strive to adapt to the expectations of their customers and international standards.
The government has also been under the equal pressure since of the advanced nature of security risks that the country may faces and the want to give assurance to people of the public that they are secure. As a technology that was considered by many members of the society as new three decades, the debate on the benefits and the shortcomings of these technologies were at the center of decisions that were made by the government agencies or organization on whether adopting biometrics technologies was a viable decision or not [4].

In Canada, the decisions to use biometric were guided by economic, operational, managerial, or, process related. According to most of the researches that were done on the adoption of biometric, these decisions were as a result of operational variables. This is further backed by the high costs that are included in the acquisition of such technologies [14]. Some managers, especially those managing small and medium-sized organizations know the security threats that their organizations face, and the benefits that they can get by adopting biometric identification and authentication but are limited by the lack of financial resources. It was also revealed that the research that informs to the ability formulation of implementation strategies might be a main factor that decreases the ability of some organizations to use biometric technologies. For most of the organizations and government agencies that adopted, security and better services were at the center of the decisions. Author in [6] argues that the money that is involved in the acquisition of this technology in Canada was not much as compared to the operational and process-related impact that it had.

\section{Summary}

Evidently, there is no single technology that will give absolute technology. Therefore, only the integration of various biometric identification options into a single application. This lead to different layered levels of security and that can lead to high layered levels of security as in the case for some of the organizations in the financial sector. The Canadian Border Services Agency has also been seen to use more than one biometrics identification technology. The use of biometric technology is advanced in Canada is more advanced than most parts of the world, especially the developing countries.

\section{THEORETICAL FRAMEWORK}

Managerial, organizational, technological and environmental imperatives are all promoted by available theories on the use of technology [12]. Notably, the adoption of biometric technologies is not entirely a technological issue because of the high influence that cost has. Therefore, this study is going to assume that adoption has six phases, which are: initiation, adoption, adaptation, acceptance, re-utilization then infusion. As far as the available literature on the adoption of biometric technology in Canada is concerned, the country is at the adaptation stage of technology adoption. The model (Rogers, 1995) include the diffusion of innovation that is commonly used in understanding the diffusion of technologies is as seen in Fig. 1 below.

\section{A. Usage}

Biometric technologies in widely used by security agencies and financial organizations in Canada. However, not much has been seen in the other sector. 


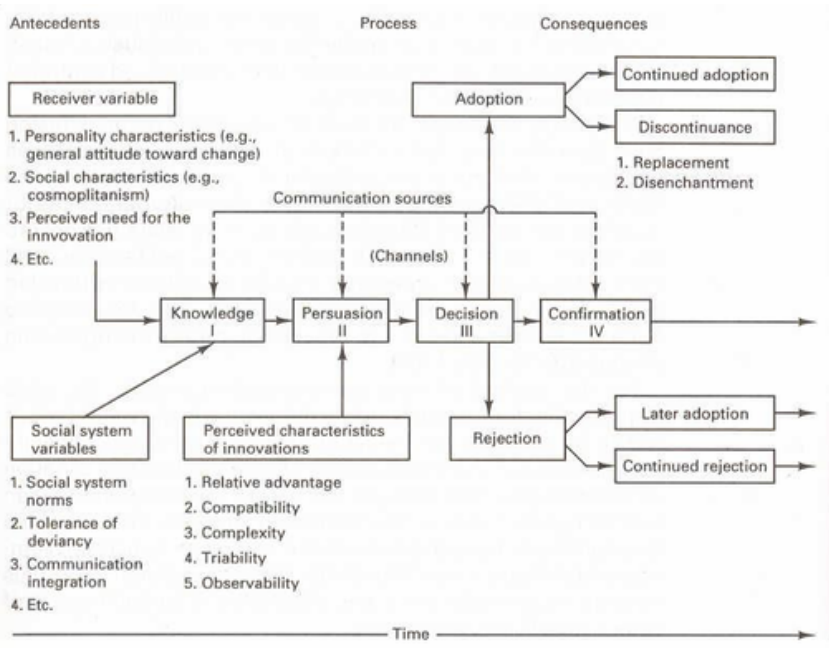

Fig. 1. Diffusion of innovation model. Source:(Rogers, 1995).

\section{B. Variables of Receivers}

The diffusion of innovation model uses organizational social characteristics, demographic characteristics, and perceived innovation need as essential variables that could have controlling impacts on the decision to adopt a technology by an organization or government agency. This study mainly focuses on organizational features such as type, size, age, and experience in IT as main factors that can affect the decision on whether or not to adopt the use of biometric technologies.

\section{Perceived Innovation Characteristics}

The diffusion of innovations theory asserts that the various dimensions of attitude toward an innovation are measurable using the five attributes, namely, compatibility, relative advantage, complexity, risk, and trialability. The perceived relative advantage of innovative technologies is directly proportional to the rate at which it is adopted [1]. Research also indicates that an innovative technology with substantial complexity needs more technical skills and needs greater implementation and operational efforts to increase its chances of adoption. Potential adopters of technology who are allowed to try an innovation will feel more comfortable with the technology and are likely to adopt it.

\section{Methodology}

\section{A. Sampling}

The sampling technique that was carried out in this study was a testing as opposed to random choosing. The study made use of three sets of samples which are financial institutions, immigration agencies, and law enforcement agencies. The choice of these sets of the sample was as a result of the high rate at which security measures and identification was of importance to these sectors. Participants were employees of the organization in the specialized IT department, especially those directly involved in the implementation of biometrics technologies. Although biometric not being a new trend in Canada, focusing on the IT specialists ensured that the data that was collected was of the maximum possible accuracy.

\section{B. Data Collection}

The data collection method that was used for this study was questionnaires. The selection of this method of data selection was directed by a high number of participants that the study willing to have and their variety in terms of age, the size of organizations in which they work, gender, and the roles that they play in these organizations [11]. The questionnaire used both open and closed questions with demographic details being of utmost importance. The questionnaires also had a section that focused on the variables concerning biometrics adoption. These variables included technology, ease of use, support of management, technological compatibility, and participant vulnerabilities and privacy needs [7]. We distributed the questionnaire to 10 organisations that have number of IT specialists. Therefore, we made up about one hundred questionnaires. One hundred thirty nine of them were filled and used for analysis and studies in this paper.

\section{Processing}

Exploratory factor analysis was used in the reduction of the number of variables into few factors that can influence the implementation of biometrics technology in an organization. The reduced factors were an improvement of service excellence, security, and productivity. Statistical Package for Social Sciences (SPSS) for Windows Version 14.0 was then used for factor analysis. The factors were also derived by principal axis factoring and rotating them by applying Promax with Kaiser Normalization method to increase the relationship between some of the factors and the variables. Multiple regression analysis was applied to test the hypotheses associated with the factors that influence implementation of biometric technologies.

\section{DATA ANALYSis}

The data that was collected from individuals from demographic perspective is as shown in Table II.

According to the data that was collected, the rate at which biometrics was adopted in the sectors that the study was based on. The findings according to the difference are presented in table three. The YY ratings imply that there was the adequate use of biometrics technologies. The Y ratings indicate that the use of biometrics was moderate while $\mathrm{N}$ rating implies that either were no cases of biometric adoption.

\section{A. Regression Analysis}

Regression analysis proved to be effective in the testing of the hypothesis. The regression analysis was based on the factors that determined the applicability and adoptability of biometrics technologies in Canada. It was from the relationship between the stated variable: technology, ease of use, support of management, technological compatibility, and participant vulnerability and privacy concerns and the state of biometric technology in the country.

\section{DISCUSSION OF FINDINGS}

According to the results of the study reveal that ease of use, size and type of organization, and communication sufficiently influenced the adoption of biometric technology. 
TABLE I. RESPONDENT CHARACTERISTICS

\begin{tabular}{|c|c|c|}
\hline Characteristics & Number & Percent \\
\hline \multicolumn{3}{|l|}{ Age } \\
\hline 25-34 years & 45 & 35.71 \\
\hline 35-44 years & 49 & 38.89 \\
\hline 45-55 years & 18 & 14.29 \\
\hline 55-65 years & 9 & 7.14 \\
\hline More than 65 years & 5 & 3.97 \\
\hline \multicolumn{3}{|l|}{ Gender } \\
\hline Male & 68 & 53.97 \\
\hline Female & 58 & 46.03 \\
\hline \multicolumn{3}{|l|}{ Type of organization } \\
\hline Financial institutions & 43 & 34.13 \\
\hline Law enforcement & 26 & 20.63 \\
\hline Immigration & 29 & 23.02 \\
\hline Others & 28 & 22.22 \\
\hline \multicolumn{3}{|l|}{ Position in organization } \\
\hline Top level management & 20 & 15.87 \\
\hline Middle management & 22 & 17.46 \\
\hline Operational level management & 30 & 23.81 \\
\hline Technical staff & 27 & 21.43 \\
\hline Operational Staff & 27 & 21.43 \\
\hline \multicolumn{3}{|l|}{ Size of organisation } \\
\hline Very small & 8 & 6.35 \\
\hline Smallmedium & 15 & 11.90 \\
\hline Medium & 19 & 15.08 \\
\hline Mediumlarge & 22 & 17.46 \\
\hline Large & 32 & 25.40 \\
\hline \multicolumn{3}{|l|}{ Age of organization } \\
\hline Less than 5 years & 7 & 5.56 \\
\hline 59 years & 15 & 11.90 \\
\hline 1019 years & 9 & 7.14 \\
\hline 2029 years & 29 & 23.02 \\
\hline 30 years and above & 28 & 22.22 \\
\hline \multicolumn{3}{|l|}{ IT experience } \\
\hline Less than 5 years & 24 & 19.05 \\
\hline 59 years & 26 & 20.63 \\
\hline 1019 years & 32 & 25.40 \\
\hline 2029 years & 21 & 16.67 \\
\hline 30 years and above & 23 & 18.25 \\
\hline
\end{tabular}

TABLE II. ADAPTION RATES INDICATIONS

\begin{tabular}{|l|l|l|l|l|}
\hline & Banking & Immigration & Law enforcement & others \\
\hline Signature & YY & Y & YY & YY \\
\hline Fingerprint & YY & YY & YY & YY \\
\hline Voice & Y & Y & YY & Y \\
\hline Face recognition & YY & YY & YY & Y \\
\hline Iris & Y & Y & N & N \\
\hline Hand and finger geometry & Y & Y & Y & Y \\
\hline Gait & N & YY & YY & Y \\
\hline DNA & N & Y & Y & Y \\
\hline Keystroke & YY & Y & Y & Y \\
\hline Retinal scanning & Y & N & Y & Y \\
\hline
\end{tabular}

Given that Canada is at the adaptation stage, there were very few participants still doubting the level of effectiveness of biometric technology in the enhancement of security. However, the participants were of the opinion that determination of the right balance in terms of the technologies to be used and the nature of organization were the major challenges that were faced when it comes to the adoption of biometric technologies.

\section{A. Expected Attributes of Biometric Technology}

1) Compatibility of the technology: Though there is the significance of technological compatibility in the adoption of biometric technology, there has not been evidence that it is of high influence. As far as infrastructure that is used in the adaptation of this technology is concerned, most of the participants seem to think that the level of advancement of information technology in Canada is enough for any organization that intends to adopt biometric technologies.

2) Use difficulty of use: Majority of the respondents were of the opinion that the difficulty of use is no longer a determining factor on whether an organization adopts biometric technology. It used to be an important determinant in the past. However, with the level of advancement of information technology in Canada, it has become easier for organizations to adopt the biometric technology. This can be proved by the high number of organizations using biometric technologies in Canada. In most developing countries, older organizations tend to avoid innovative technologies because they are satisfied with the traditional techniques of identification and authentication. However, the situation in Canada is different because the older organizations are taking advantage of massive experience and access to capital that they can use in the adoption of biometric technology. This is an opinion that was held by $72.22 \%$ of the participants.

3) Relative advantage: Relative advantage proved to be of high influence on the adoption of biometric technology. Most of the participants were of the impression that their organizations opted for biometric technologies because of the fact that they provide identification and authentication advantages that none of the available alternatives could. Only $17.26 \%$ of the participants thought that potential relative advantage had no impact on the decision whether to adopt biometric technologies.

\section{B. Variables of Social Systems}

Suitable communication between information technology experts and users and organization managers is considered to be one of the principal factors that have contributed to the high level of adoption of biometric technology in Canada. 86\% of the participants were adamant that lack of understanding of the technologies was a high contribution to the low rate at which these technologies were adopted in the past. Management support was also of significance because of the level to which management influence the strategies that are adopted and the extent to which they are adopted. This is a trend that proved to be persistent for participants who worked in government agencies.

\section{Receiver Variables}

As seen in the result, organizational demographic nature tends to have minimal influence its intention to use the biometric technology. There is no evidence from the collected data that can prove that the age of the organization had an influence on the decision to opt for biometric technology. 
However, there was some difference when it comes to the size of the organization. The larger organizations in Canada appeared to adopt biometric technology at a higher rate as compared to the smaller ones. This difference can be attributed to the difference in access to resources.

\section{CONCLUSION}

Evidently, the use of biometric technologies in Canada has gotten to its adaptation stage. The level of understanding of the participants and the number of organizations that use these technologies is enough proof that the country is way past the infancy stage. However, it is clear that the nature of the organization and its goals in terms of identification and authentication was of high influence on the adoption of biometrics technology. This is the reason why the technologies are widely used in the banking, immigration, and law enforcement sectors. This proves the hypothesis that economic, operational, managerial, or, process factors determined the possibility of an organization adopting biometric technologies.

\section{REFERENCES}

[1] Hossein Bidgoli. The introduction of biometrics security into organizations: A managerial perspective. International Journal of Management, 29(2):687, 2012.

[2] Michael Colin Breward. Factors influencing consumer attitudes towards biometric identity authentication technology within the Canadian banking industry. $\mathrm{PhD}$ thesis, 2009.

[3] Hyunbae Chun. Information technology and the demand for educated workers: disentangling the impacts of adoption versus use. Information Technology, 85(1), 2006.
[4] Kathrin Cresswell and Aziz Sheikh. Organizational issues in the implementation and adoption of health information technology innovations: an interpretative review. International journal of medical informatics, 82(5):e73e86, 2013.

[5] Ana Ortiz De Guinea and M Lynne Markus. Why break the habit of a lifetime? rethinking the roles of intention, habit, and emotion in continuing information technology use. Mis Quarterly, pages 433444, 2009.

[6] Stephen J Elliott, Sarah A Massie, and Mathias J Sutton. The perception of biometric technology: A survey. In Automatic Identification Advanced Technologies, 2007 IEEE Workshop on, pages 259264. IEEE, 2007.

[7] Inkingi Fred Gatali, Kyung Young Lee, Sang Un Park, and Juyoung Kang. A qualitative study on adoption of biometrics technologies: Canadian banking industry. In Proceedings of the 18th Annual International Conference on Electronic Commerce: e-Commerce in Smart connected World, page 20. ACM, 2016.

[8] Rajeev Gupta and Ashok Kumar. Noisy iris recognition and its importance. J. Ultra Sci. Phys. Sci, 25(2):229234, 2013.

[9] Kim Kristian Humborstad. How governments are creating the business case for biometrics. Biometric Technology Today, 2015(7):911, 2015.

[10] Nancy Lewis. Expanding surveillance: Connecting biometric information systems to international police cooperation. Global Surveillance and

[11] Shoshana Magnet. When biometrics fail: Gender, race, and the technology of identity. Duke University Press, 2011.

[12] Jonathan I Mitchell, Marylne Gagn, Anne Beaudry, and Linda Dyer. The role of perceived organizational support, distributive justice and motivation in reactions to new information technology. Computers in Human Behavior, 28(2):729738, 2012.

[13] Cristian Morosan. Biometric solutions for todays travel security problems. Journal of Hospitality and Tourism Technology, 3(3):176195, 2012.

[14] G Premkumar and Anol Bhattacherjee. Explaining information technology usage: A test of competing models. Omega, 36(1):6475, 2008. 